\title{
AS CONTRIBUIÇÕES DE NORBERTO BOBBIO E DE LUIGI FERRAJOLI À SOBERANIA DE HANS KELSEN
}

THE CONTRIBUTINOS OF NORBERTO BOBBIO AND LUIGI FERRAJOLI TO HANS KELSEN'S SOVEREIGNTY

LAS CONTRIBUCIONES DE NORBERTO BOBBIO Y DE LUIGI FERRAJOLI A LA SOBERANÍA DE HANS KELSEN

Clovis Demarchi ${ }^{1}$ Fabrício Wloch ${ }^{2}$

Resumo: Este artigo científico investiga o conceito de Soberania do ponto de vista de grandes autores contemporâneos, Kelsen, Ferrajoli e Bobbio. A importância do tema é estabelecer os aprimoramentos trazidos por Bobbio e Ferrajoli ao conceito de Soberania originalmente estudado por Kelsen. $\mathrm{Na}$ primeira parte caracterizaram-se os elementos identificadores da Soberania. Na segunda tratou-se da Soberania vista pelo austríaco Hans Kelsen, tida como inerente ao poder do Estado e como manifestação da validade e da eficácia do ordenamento jurídico, que pode ser limitado apenas pelo Direito Internacional. Na terceira parte foi trazida a visão do italiano Norberto

1 Doutor e Mestre em Ciência Jurídica pela Universidade do Vale do Itajaí. Professor na graduação em Direito e no Mestrado e Doutorado em Ciência Jurídica da Univali. Líder do grupo de pesquisa em Direito Educacional e Normas Técnicas e membro do grupo de pesquisa em Direito, Constituição e Jurisdição. Endereço eletrônico: demarchi@univali.br

2 Doutorando e Mestre em Ciência Jurídica do Programa de Pós-Graduação Stricto Sensu em Ciência Jurídica da Universidade do Vale do Itajaí (Univali). Servidor do Tribunal de Justiça do Estado de Santa Catarina. Endereço eletrônico: fwloch@edu.univali.br 
Bobbio, que destaca a contradição entre Soberania e constitucionalismo e democracia. Na quarta descreveram-se os aspectos da Soberania estatal do ponto de vista do também italiano Luigi Ferrajoli, que aborda o tema de modo histórico e bélico. Na quinta parte correlacionaram-se as três posições, de modo a distinguir a melhor via para se construir um novo conceito adaptado à modernidade e inspirado no sociólogo e humanista Edgar Morin. No que se refere à Metodologia, o trabalho foi desenvolvido em base lógica indutiva. A pesquisa foi bibliográfica e documental.

Palavras-chave: Estado, Soberania, Direito Internacional, Constitucionalismo, Democracia, Guerra

Abstract: This scientific paper investigates the concept of sovereignty from the perspective of the leading contemporary authors, Kelsen, Ferrajoli and Bobbio. The importance of the issue is to establish the improvements brought by Bobbio and Ferrajoli to the concept of sovereignty originally studied by Kelsen. The first part of this paper characterizes the identifying elements of sovereignty. The second part addresses Sovereignty as understood by the Austrian Hans Kelsen, who regards it as inherent to the power of the state, and as a manifestation of the validity and effectiveness of the legal system, which can be limited by international law. The third part brings the perspective of the Italian author Norberto Bobbio, which highlights the contradiction between sovereignty and constitutionalism and democracy. The fourth section describes the aspects of state sovereignty from the point of view of Luigi Ferrajoli, a fellow Italian, who addresses the theme from a historical and bellic perspective. The fifth part describes the three positions, in order to distinguish the best way to build a new concept adapted to modernity and inspired by the sociologist and humanist Edgar Morin. In terms of methodology, the work was based on inductive logic. Bibliographic and document research were also used.

Keywords: State Sovereignty, International Law, Constitutionalism, Democracy, War. 
Resumen: Este artículo científico investiga el concepto de Soberanía desde el punto de vista de grandes autores contemporáneos, Kelsen, Ferrajoli y Bobbio. La importancia del tema es establecer los perfeccionamientos aportados por Bobbio y Ferrajoli al concepto de Soberanía originalmente estudiado por Kelsen. En la primera parte se caracterizaron los elementos identificadores de la Soberanía. En la segunda, se trató de la Soberanía vista por el austríaco Hans Kelsen, considerada como inherente al poder del Estado y como manifestación de la validez y de la eficacia del ordenamiento jurídico, que solo puede ser limitado por el Derecho Internacional. En la tercera parte se expuso la visión del italiano Norberto Bobbio, que destaca la contradicción entre Soberanía y constitucionalismo y democracia. En la cuarta, se describieron los aspectos de la Soberanía estatal desde el punto de vista del también italiano Luigi Ferrajoli, que aborda el tema de modo histórico y bélico. En la quinta parte se correlacionaron las tres posiciones para poder distinguir la mejor vía para construir un nuevo concepto adaptado a la modernidad e inspirado en el sociólogo y humanista Edgar Morin. En lo que se refiere a la Metodología, el trabajo fue desarrollado sobre una base lógica inductiva. La investigación fue bibliográfica y documental.

Palabras clave: Estado; Soberanía; Derecho Internacional; Constitucionalismo; Democracia; Guerra.

\section{INTRODUÇÃO}

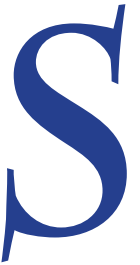
abe-se que a Soberania tem sido superada e debatida pelas modernas teorias políticas e jurídicas e também pela jurisprudência. O problema enfrentado consiste em analisar como Hans Kelsen pensava a Soberania dos Estados quando escreveu sua obra Teoria Geral do Direito e do Estado (1945) e como Bobbio e Ferrajoli posicionam-se a respeito nos tempos atuais.

Como hipótese supõe-se que Ferrajoli e Bobbio ajustaram e adaptaram os elementos de Soberania formulados por Kelsen, atualizando-a de acordo com as exigências do paradigma do Estado moderno, em especial, do Constitucionalismo e da Democracia.

O presente artigo tem por objeto as contribuições de Bobbio e Ferrajoli para o conceito de Soberania dos Estados à luz de Kelsen. O objetivo geral é analisar 
as contribuições de Norberto Bobbio e Luigi Ferrajoli para os estudos de Hans Kelsen no que tange à Soberania. O específico é descobrir se tal conceito foi aprimorado com o passar o tempo e como ele se encaixa nos tempos atuais.

No primeiro momento, traça-se um panorama sobre o conceito de Soberania. No segundo, versa-se a respeito da posição de Kelsen de que a Soberania, como componente inerente ao poder do Estado, é a manifestação da validade e da eficácia do ordenamento jurídico, que é o que determina o modo de exercer o poder e os seus limites, limitado apenas pelo Direito Internacional.

No terceiro momento, fala-se a respeito da Soberania pensada por Norberto Bobbio para quem as técnicas do constitucionalismo - Estado misto, separação dos poderes, supremacia da lei - tendem à divisão e ao equilíbrio do poder entre os órgãos do Estado, combatendo a unificação e a concentração de poder, justamente o que é pregado pela noção clássica de Soberania.

No quarto relacionam-se as reflexões de Luigi Ferrajoli sobre a Soberania, que sublinha um paulatino esvaziamento da Soberania estatal desde a Revolução Francesa e, atualmente, mais ainda em razão dos acordos entre nações movidos por motivos econômicos, muito embora o Direito Internacional careça de coação.

No quinto e último momento faz-se um apanhado dos três pensamentos, buscando a partir de Hans Kelsen uma análise crítica dos pontos em que Bobbio e Ferrajoli vieram a complementá-lo em contraste com as vias sugeridas pelo sociólogo e humanista Edgar Morin.

No que se refere à Metodologia ${ }^{3}$, foi desenvolvido sob o método indutivo e operacionalizado mediante pesquisa bibliográfica e documental. Este trabalho concentrou-se na área de Constitucionalismo, Transnacionalidade e Produção do Direito

\section{SOBERANIA}

O conceito clássico de Soberania aparece no momento de afirmação do Estado nacional e permanece com ele sem grandes mudanças, compreendido como 3 PASOLD, Cesar Luiz. Metodologia da Pesquisa Jurídica: Teoria e Prática. 13. ed. Florianópolis: Conceito Editorial, 2015. p. 85. 
corolário do exercício do poder do Estado. Na definição de Kelsen4: "Uma ordem jurídica relativamente centralizada, limitada no seu domínio espacial e temporal de vigência soberana ou imediata relativamente ao Direito Internacional e que é, globalmente ou de um modo geral, eficaz".

A Soberania como elemento do Estado, para Dallari ${ }^{5}$, é o centro unificador da ordem, o núcleo de vontade e controle do Estado, que dirige a Sociedade aos seus fins comuns dentro da ordem. Como ao Estado não se devem sobrepor outros poderes, diz-se que a Soberania é o poder incontrastável do Estado.

Caetano $^{6}$ utiliza a ideia de que Soberania é o "poder político supremo independente". A Soberania seria para ele a "plenitude do poder político" por entender que pode existir Estado não soberano. Isso se passa, segundo ele, com os "Estados federados e os Estados protegidos".

Um Estado federado difere de Estado soberano por transferir parte de seus poderes soberanos para o governo federal. Um Estado federado tem competência administrativa sobre um território geográfico definido. Exemplos de países que são subdivididos por estados federais são Brasil e Índia. Já o Estado protegido, ou protetorado, é um território autônomo que é protegido diplomática ou militarmente contra terceiros por um Estado ou ente mais forte. Para tanto, o protetorado geralmente aceita obrigações específicas, dependendo da natureza de seu relacionamento, porém mantém a soberania formal e continua a ser um Estado sob a lei internacional. Como exemplos, cita-se que a Agência de Proteção Ambiental dos Estados Unidos usa o termo protetorado quando se refere a regiões insulares daquele país, tais como Porto Rico e as Filipinas.

Já Sassen escreve: "State sovereignty is usually understood as the State's monopoly of authority over a particular territory, demarcated by reasonably established geographic borders"7.

4 KELSEN, Hans. Teoria Pura do Direito. Tradução de João Baptista Machado. 7. ed. São Paulo: Martins Fontes, 2006. p. 321.

5 DALLARI, Dalmo de Abreu. Elementos de teoria geral do Estado. Elementos de Teoria geral do Estado. 19. ed. São Paulo: Saraiva, 1995. p. 68-69.

6 CAETANO, Marcello. Manual de Ciência Política e Direito Constitucional. 4. ed. Lisboa: Coimbra Editora,1963. p. 108-109.

7 "Soberania do Estado é geralmente entendida como o monopólio de autoridade do Estado sobre um determinado território, demarcado por fronteiras geográficas razoavelmente es- 
Hodiernamente, o conceito tradicional de Soberania tem sido modificado pelas modernas teorias políticas e jurídicas e também pela jurisprudência ao analisar demandas sobre Direito Internacional.

Isso é reflexo da crise do Estado, isto é, da mudança que se opera na forma de se compreender o Estado, desde o absolutismo até o surgimento do modelo comunitário de organização social, resultado da globalização.

Passa-se a delinear o que Kelsen tinha por certo a respeito da Soberania.

\section{SOBERANIA EM HANS KELSEN}

Hans Kelsen (Praga, 11 de outubro de 1881 - Berkeley, 19 de abril de 1973) foi um jurista e filósofo austríaco, tido como um dos mais influentes estudiosos do Direito. Sua influência abrange os campos da filosofia, da ciência jurídica, da sociologia, da teoria da democracia e das relações internacionais.

Kelsen escreve sobre Soberania em um contexto no qual, dentro das teorias jurídicas e políticas, quase não se discute mais a submissão do poder político ao ordenamento jurídico. O Estado de Direito já é um fato consumado historicamente.

Além dos mecanismos de contenção do poder, o que estava em voga quando Kelsen trata do assunto é a criação de mecanismos jurídicos que façam o Estado agir positivamente dentro da sociedade: o Estado Social está no seu período de afirmação como paradigma de Estado. Por isso, a ideia de Soberania como poder ilimitado deve ser vista à luz da teoria jurídica contemporânea, já não há poder do Estado que não esteja submetido ao ordenamento jurídico, ao império da lei, cuja maior expressão é a Constituição.

Ao mesmo tempo, Kelsen quer afirmar a possibilidade de uma ciência do Direito, balizada nos critérios de pureza, de isenção ideológica e de objetividade determinados pela epistemologia advinda da filosofia analítica, principalmente tabelecidas" (tradução livre) SASSEN, Saskia. Bordering Capabilities versus Borders: Implications for National Borders. 30 Michigan Journal of International Law (2008-2009). p. 567-597. 
aquela que decorre da filosofia praticada pelos neokantianos e pelos integrantes do Círculo de Viena.

Logo, Kelsen está focado em descrever o fenômeno jurídico sem levar em consideração seus aspectos políticos, morais ou ideológicos. Para isso trata o direito de modo apenas formal, possibilitando uma verdadeira ciência jurídica. Isso significa que não é sua preocupação identificar fatores reais de poder.

O Estado é um agregado de indivíduos, um povo, que vive dentro de certa parte delimitada da superfície da Terra, e que está sujeito a certo poder. Ou seja, um Estado é composto pelo território, pelo povo e por um poder de governo. $O$ poder do Estado ao qual o povo está sujeito é a validade e a eficácia da ordem jurídica, de cuja unidade resulta a unidade do território e a do povo. O poder do Estado deve ser a validade e a eficácia da ordem jurídica nacional, caso a Soberania deva ser considerada uma qualidade desse poder. Isso porque a Soberania só pode ser a qualidade de uma ordem normativa na condição de autoridade que é a fonte de obrigações e de direitos ${ }^{8}$.

Kelsen aponta no sentido de que só é possível identificar o poder soberano no ordenamento jurídico, porque aquele que tem o poder de emitir comandos obrigatórios para todos os cidadãos o faz por determinação de uma ordem jurídica que fundamenta esse seu direito?.

É bom dizer então que o problema da classificação das formas de governo é uma questão de identificar a quem é dado o poder de legislar pela constituição. Logo, se a constituição determina que uma só pessoa será o legislador, então o governo é monárquico; se um grupo minoritário deve legislar, o governo é aristocrático; se a maioria é a legisladora, o governo é democrático. Isso porque "o poder do Estado é a validade e eficácia da ordem jurídica"10. O ordenamento

8 KELSEN, Hans. Teoria Geral do Direito e do Estado. 2. ed. (19a reimpressão), trad. Luís Carlos Borges, São Paulo: Martins Fontes, 1995, p. 249 e 250.

9 KELSEN, Hans. Teoria Geral do Direito e do Estado, p. 371. "A afirmação de que a soberania é uma qualidade essencial do Estado significa que o Estado é uma autoridade suprema. A 'autoridade' costuma ser definida como o direito ou poder de emitir comandos obrigatórios". Mas, para que se exerça esse poder, alguém tem de ter recebido o direito de emitir esses comandos obrigatórios. Porém, esse direito só pode ser conferido por uma ordem jurídica. "Desse modo, a autoridade, originalmente é característica de uma ordem normativa. Apenas uma ordem normativa pode ser 'soberana', ou seja, uma autoridade suprema, o fundamento último de validade das normas que um indivíduo está autorizado a emitir como 'comandos' e que outros são obrigados a obedecer".

10 KELSEN, Hans. Teoria Geral do Direito e do Estado, p. 277. 
jurídico é que determina a organização do Estado e quem exercerá a função legislativa. E o principal instrumento para isso é a constituição.

Para Kelsen, a discussão a respeito da Soberania passa, em primeiro lugar, pela discussão da identificação do Direito Internacional. Segundo o jurista austríaco, não há como negar a existência do Direito Internacional, pois, além de os Estados poderem celebrar entre si tratados (Direito Internacional parcial), existem normas de caráter consuetudinário que valem para todos os Estados genericamente, normas que os Estados não podem isoladamente determinar. Por exemplo, Kelsen cita as normas de direito marítimo e o fato de um Estado só poder ser reconhecido como tal pelo ordenamento internacional ${ }^{11}$.

Tanto que o conteúdo material das normas jurídicas do direito interno pode ser limitado ou determinado pela ordem internacional, de forma que aquele fica limitado por este. Nas palavras de Kelsen:

O Direito Internacional é relevante também para a esfera de validade da ordem jurídica nacional. Como as suas normas, especialmente as criadas por tratados internacionais, podem regulamentar qualquer matéria e, portanto, também as matérias regulamentadas pelo Direito nacional, ele limita a esfera de validade material deste último. Os Estados, é verdade, permanecem competentes, mesmo sob o Direito Internacional, para regulamentar em princípio todas as matérias que podem ser regulamentadas por uma ordem limitada na sua esfera territorial; mas eles conservam essa competência apenas na medida em que o Direito Internacional não regulamente uma matéria específica. $O$ fato de uma matéria ser regulamentada pelo Direito Internacional tem o efeito de que esta não pode ser regulamentada arbitrariamente pelo direito nacional ${ }^{12}$.

Entretanto, não basta que a ordem internacional limite a atividade do ordenamento jurídico nacional para ser reconhecida como direito. É necessário que suas normas sejam dotadas das características que devem ter todas as

11 KELSEN, Hans. Teoria Geral do Direito e do Estado, p. 341: "Na verdade, é pelo Direito internacional que são determinadas as esferas de validade territorial e pessoal, assim como a temporal, das ordens jurídicas nacionais".

12 KELSEN, Hans. Teoria Geral do Direito e do Estado, p. 341. A partir dessa passagem Kelsen conceitua juridicamente o Estado: "A ordem jurídica nacional, isto é, uma ordem que constitui um Estado, pode, desse modo, ser definida como uma ordem coercitiva relativamente centralizada cujas esferas de validade territorial, pessoal e temporal são determinadas pelo Direito internacional e cuja esfera de validade material é limitada apenas pelo Direito internacional. Trata-se de uma definição jurídica de Estado" (p. 342). 
normas jurídicas. Esses atributos incluem pertencer a um ordenamento com poder de coerção e, consequentemente, ser dotada de sanção. Para Kelsen, o que caracteriza a norma jurídica é prever uma punição como consequência de um ato proibido que pode ser imposto por um poder externo de coerção, isto é, mediante o uso da força, que, nesse caso, é legitimada pelo direito ${ }^{13}$.

Considerando que a ordem jurídica internacional é descentralizada, Kelsen afirma que ela é uma ordem jurídica primitiva, assim como as ordens jurídicas tribais. Não existe um órgão dotado de poder de coação; apenas aquele que foi ofendido fica legitimado a impor represálias ou fazer a guerra contra seu ofensor. É a ideia de que a guerra só pode ser exercida se for por uma causa justa. Se não for uma reação a um ilícito internacional, a guerra passa a ser um ilícito. Portanto, se um Estado comete um ilícito, o Estado ofendido tem o direito de declarar guerra ou impor-lhe represálias.

O Direito Internacional possui a técnica da iniciativa individual. O Estado, violado no seu direito, está autorizado a agir contra o violador, lançando mão da guerra ou das represálias. Estas são as sanções específicas providas pelo Direito Internacional geral14.

Quando isso acontece, o Estado ofendido exerce a função de um órgão da comunidade internacional, pois só tem o direito de impor a sanção porque legitimado pelo reconhecimento do ilícito proibido pela ordem jurídica internacional. Mas Kelsen admite que o Direito Internacional pode evoluir, criando instituições jurídicas que venham a constituir uma espécie de "Estado mundial"15.

Uma vez alicerçada a existência do Direito Internacional, Kelsen desafia as doutrinas que o relaciona com o direito nacional. É contra a doutrina dualista, pois não admite que possam existir duas ordens jurídicas independentes, já que, além da ordem jurídica internacional fundamentar as esferas de validade dos ordenamentos nacionais e poder limitar a validade material, os próprios dualistas 13 KELSEN, Hans. Teoria pura do direito. Trad. João Baptista Machado, 6. ed. São Paulo: Martins Fontes, 1998. p. 35-65.

14 KELSEN, Hans. Teoria Geral do Direito e do Estado, p. 318.

15 KELSEN, Hans. Teoria Geral do Direito e do Estado, p. 317. "Ou seja, que a ordem jurídica efetivamente válida venha a ser transformada, por meio da centralização, numa ordem jurídica nacional cuja esfera territorial de validade coincida com o Direito internacional efetivamente válido". 
admitem que, uma vez aprovada internamente, o Direito Internacional tem vigência para o Estado, o que demonstra que existe apenas uma ordem jurídica geral. Só pode prevalecer, assim, a doutrina monista, que possui duas vertentes: a que defende a primazia do Direito Internacional e a que defende a primazia do direito nacional.

Kelsen, muito embora afirme sua preferência pela primeira vertente, diz que ambas são cientificamente defensáveis. E dessas duas vertentes é que saem as características da Soberania no pensamento kelseniano.

Como visto, ele recusa que um poder físico possa ser considerado soberano. Isso porque, se assim fosse, ele teria de ser a causa primeira da formação do ordenamento jurídico. Para Kelsen não se pode determinar a causa primeira; a ideia de Soberania como poder físico não passa de uma ilusão, pois, se não pode haver nenhuma causa primeira, não poderia haver Soberania.

Disso decorre que:

O Estado na sua capacidade de autoridade jurídica deve ser idêntico à ordem jurídica nacional. Dizer que o Estado é soberano significa que a ordem jurídica nacional é uma ordem acima da qual não existe nenhuma outra. A única ordem que se poderia supor como sendo superior à ordem jurídica nacional é a ordem jurídica internacional. Assim, a questão de saber se um Estado é soberano ou não coincide com a questão de saber se o Direito Internacional é ou não ordem superior ao Direito nacional ${ }^{16}$.

Nesse sentido, Kelsen admite como defensável as duas correntes monistas. A existência da Soberania é só uma hipótese decorrente da escolha de uma dessas duas teorias. Sob a conjetura da primazia do Direito Internacional, a Soberania só pode ser entendida relativamente, isto é, como um ordenamento que só reconhece como superior o internacional, nenhum outro. Sob a suposição da primazia do Direito nacional, "o Estado é soberano no sentido absoluto, original do termo, sendo superior a qualquer outra ordem, inclusive ao Direito Internacional"17.

Vê-se então que a Soberania, para Hans Kelsen, não é exercida por um indivíduo ou por um grupo deles. A Soberania, como componente inerente ao 16 KELSEN, Hans. Teoria Geral do Direito e do Estado, p. 372.

17 KELSEN, Hans. Teoria Geral do Direito e do Estado, p. 373. 
poder do Estado, é a manifestação da validade e da eficácia do ordenamento jurídico, que é o que determina o modo de exercer o poder e os seus limites. $\mathrm{E}$ esse ordenamento poderia ser limitado apenas pelo Direito Internacional.

\section{SOBERANIA EM NORBERTO BOBBIO}

Norberto Bobbio (Turim, 18 de outubro de 1909 - Turim, 9 de janeiro de 2004) foi um filósofo político, historiador do pensamento político, escritor e senador vitalício italiano. Foi conhecido por sua ampla capacidade de produzir escritos concisos, lógicos e densos. Foi defensor da democracia socialista liberal e do positivismo legal e crítico de Marx, do fascismo italiano e do Bolchevismo.

No contexto do surgimento do Estado Moderno, segundo Bobbio, a Soberania pode ser tida como o poder de comando de derradeira instância, numa sociedade política e, consequentemente, a diferença entre esta e as demais organizações humanas, nas quais não se encontra este Poder supremo. Em uma significação moderna, o termo Soberania aparece no final do Século XVI junto com o Estado absoluto para caracterizar o Poder estatal ${ }^{18}$.

Para Bobbio, "em sentido lato, o conceito político-jurídico de Soberania indica o poder de mando de última instância, numa sociedade política [...]"19. É poder absoluto, perpétuo, imprescritível, inalienável e indivisível ${ }^{20}$. É a partir dessa ideia, em conjunto com as noções de território e povo, que se estrutura o Estado moderno. Daí o porquê de Bobbio também afirmar que o termo Soberania indica, "[...] em toda sua plenitude, o poder estatal, sujeito único e exclusivo da política"21.

Não sem razão Bobbio afirma que "Soberania e constitucionalismo foram sempre entendidos como termos antitéticos [...]"22. Lembra o autor italiano que as técnicas do constitucionalismo (Estado misto, separação dos poderes,

18 BOBBIO, Norberto; MATTEUCCI, Nicola; PASQUINO, Gianfranco. Dicionário de política. Tradução de Carmen C. Varriale et al. 13. ed. Brasília: UnB, 2008. Título original: Dizionario di política. $2 \mathrm{v}$.

19 BOBBIO, Norberto et al. Dicionário de política.p. 1179.

20 BOBBIO, Norberto et al. Dicionário de política. p. 1181.

21 BOBBIO, Norberto et al. Dicionário de política. p. 1179.

22 BOBBIO, Norberto et al. Dicionário de política. p. 1186. 
supremacia da lei) tendem à divisão e ao equilíbrio do poder entre os órgãos do Estado, combatendo a unificação e a concentração de poder apregoadas pela noção clássica de Soberania ${ }^{23}$.

É nesse mister que Bobbio indica a teoria pluralista como o verdadeiro adversário político da Soberania. Nas palavras do autor:

As concepções pluralistas - quer as descritivas que objetivam a percepção do processo real de formação da vontade política, quer as prescritivas que objetivam maximizar a liberdade numa sociedade democrática por meio de uma poliarquia - demonstram a não existência de uma unidade do Estado, que possua o monopólio de decisões autônomas, uma vez que, na prática, o indivíduo vive em associações e grupos diferentes, capazes de impor suas próprias opções. Na realidade, o contexto social apresenta uma notável pluralidade de grupos em competição ou em conflito para condicionar o poder político; é justamente esta pluralidade que impede a existência de uma única autoridade, onicompetente e onicompreensiva: o processo de decisão política é o resultado de uma longa e vasta série de mediações. Nesta divisão do poder, nesta poliarquia, não existe um verdadeiro soberano ${ }^{24}$.

Bobbio admite que, tanto a compatibilização conceitual entre o liberalismo e a democracia quanto a compreensão desta como desenvolvimento natural e auspicioso do Estado liberal só são possíveis "se [a democracia for] tomada não pelo lado de seu ideal igualitário, mas pelo lado de sua fórmula política, que é, como se viu, a Soberania popular"25.

Convém notar, outrossim, que a invocação da Soberania popular não passa de retórica vazia, pois o próprio Bobbio explica que o liberalismo dos modernos e a democracia dos antigos foram, com frequência, antitéticos, na medida em que os liberais historicamente exprimiram uma profunda desconfiança para com toda forma de governo popular, o que os motivou a defender severas restrições no exercício do direito ao sufrágio ${ }^{26}$. Como se não bastasse, para Bobbio, a associação de ambos os termos implica o dever de interpretar a palavra democracia no seu sentido jurídico-procedimental e não no sentido ético.

23 BOBBIO, Norberto et al. Dicionário de política. p. 1185.

24 BOBBIO, Norberto et al. Dicionário de política. p. 1186.

25 BOBBIO, Norberto. Liberalismo e democracia. São Paulo: Brasiliense, 2006a. p. 42-43.

26 BOBBIO, Norberto. Liberalismo e democracia. p. 38. 
Para Bobbio, "tanto a democracia direta quanto a indireta descendem do mesmo princípio da Soberania popular, apesar de se distinguirem pelas modalidades e pelas formas com que essa Soberania é exercida"27.

Com a crise desta concepção de Soberania, vários autores indicam uma leitura atenta dos fenômenos políticos que estão ocorrendo. Parafraseando Bobbio, é preciso proceder a uma nova síntese jurídico-política capaz de racionalizar e disciplinar juridicamente as novas formas de Poder, as novas autoridades que estão surgindo ${ }^{28}$. O autor italiano destaca que:

O golpe maior veio das chamadas comunidades supranacionais, cujo objetivo é limitar fortemente a Soberania interna e externa dos Estados-membros; as autoridades 'supranacionais' têm a possibilidade de conseguir que adequadas Cortes de Justiça definam e confirmem a maneira pela qual o direito 'supranacional' deve ser aplicado pelos Estados em casos concretos" 29 .

Como se depreende, Bobbio descortina a crise da Soberania estatal tendo em vista as mudanças que presenciava no cenário internacional, que vem a chamar inclusive de "nova Soberania", prevendo que a colaboração internacional, cada vez mais intensa, desgasta os poderes tradicionais dos Estados ditos soberanos.

\section{SOBERANIA EM LUIGI FERRAJOLI}

Luigi Ferrajoli (Florença, 6 de agosto de 1940) é um jurista italiano e o principal teórico do Garantismo. Define-se como um juspositivista crítico. Atuou como juiz entre 1967 e 1975, período ligado ao grupo "Magistratura democrática", uma associação de juízes de orientação progressista. A partir de 1970, foi professor de Filosofia do Direito e Teoria Geral do Direito na Universidade de Camerino, na qual também foi diretor da "Facoltà di giurisprudenza". Desde 2003, leciona na Universidade de Roma Tre.

Ferrajoli apoia-se na atualidade das ideias de Soberania tidas pelo teólogo espanhol Francisco de Vitória ${ }^{30}$. A contribuição de Francisco estaria em três 27 BOBBIO, Norberto. Liberalismo e democracia. p. 34.

28 BOBBIO, Norberto et al. Dicionário de política. p. 1188.

29 BOBBIO, Norberto et al. Dicionário de política. p. 1.187.

30 Francisco de Vitória (Burgos ou Vitória, 1483, Salamanca, 12 de agosto de 1546) foi um teólogo espanhol neoescolástico e um dos fundadores da tradição filosófica da chamada 
formulações: a existência de Estados soberanos independentes que se relacionam numa sociedade internacional; a existência de um direito natural das gentes e dos povos; e a questão de cada Estado ser capaz, em dadas circunstâncias, de empreender guerras justas. Ferrajoli aponta que será a partir destas formulações que a guerra é "o fundamento e o critério para a identificação do Estado" ${ }^{31}$.

Partindo dasnoções deSoberania internae Soberania externa, Ferrajoliapresenta os limites e as possibilidades do estabelecimento de um constitucionalismo de Direito Internacional. Nas palavras do autor:

A superação do Estado de natureza, internamente, e sua conservação (ou melhor, instauração), externamente, tornam-se, assim, as duas coordenadas ao longo das quais se desenrola a história teórica e prática dos Estados soberanos modernos, ambas inscritas no código genético de tais Estados pela filosofia política jusnaturalista ${ }^{32}$.

Como forma de inferir suas ponderações a respeito das mudanças e dos caracteres da Soberania moderna, Ferrajoli aborda a questão da Soberania externa e da Soberania interna situando-as no que chama "Era Liberal".

A Soberania interna diz respeito ao desenvolvimento das estruturas jurídicas que teriam alicerçado o Estado constitucional ao final do século XVIII. A Declaração dos Direitos do Homem e do Cidadão, em 1789, teria sido o primeiro passo para a dissolução da Soberania no âmbito interno. A partir daí, segundo Ferrajoli, a relação entre súdito e soberano se torna uma relação entre Estado e cidadão, ambos sujeitos de Soberania limitada.

Estas mudanças acarretam um definitivo "esvaziamento" do princípio de Soberania, uma vez que ele entende a Soberania como a "ausência de limites e

"Escola de Salamanca", sendo também conhecido por suas contribuições para a teoria da Guerra Justa e como um dos criadores do moderno direito internacional moderno. Foi, além de filósofo e teólogo, jurista. Lecionou no Colégio de Saint Jacques, em Paris, onde conheceu os humanistas Erasmo de Roterdã e Juan Luís Vives. Também ensinou no Colégio de San Gregório de Valladolid, em Salamanca, Espanha (BIOGRAFIAS. Dicionário de Filosofia de Cambridge. Disponível em: < http://educacao.uol.com.br/biografias/francisco-devitoria.htm >. Acesso: 10 mar. 2017).

31 FERRAJOLI, Luigi. A soberania no mundo moderno. Tradução de Carlo Coccioli e Márcio Lauria Filho. São Paulo: Martins Fontes, 2002. p. 13.Título original: La sovranità nel mondo moderno.

32 FERRAJOLI, Luigi. A soberania no mundo moderno. p. 25. 
de regras" 33 . Porém, ele assevera que, contraditoriamente, no plano doutrinário, "a ideia de Soberania interna reforça-se decididamente"34.

A Soberania externa, por sua vez, alcança seu cume entre meados do século XIX e meados do século XX. É neste período que ela "liberta-se definitivamente [...] de qualquer vínculo ou freio jurídico"35. Isso porque as relações entre os Estados no século XIX acontecem de maneira que nenhum Estado está vinculado a qualquer princípio ou norma que os freie na busca de seus interesses.

Noutro giro, após a Segunda Guerra dos Trinta anos - ou Guerra Civil Europeia (1914-1945) - e com o estabelecimento da ONU e a Declaração Universal dos Direitos do Homem, as relações entre os Estados passam de um "Estado de natureza para um Estado civil": a Soberania "deixa de ser uma liberdade absoluta e selvagem e se subordina, juridicamente, a duas normas fundamentais", o imperativo da paz e a tutela dos direitos humanos ${ }^{36}$. É quando ocorre para Ferrajoli a "crise hodierna da Soberania".

Ferrajoli sustenta que a Carta da ONU pode ser interpretada como "um verdadeiro contrato social internacional", na medida em que estabelece vínculos entre os Estados e uma ordem verdadeiramente universalista. Apesar da aparente ingenuidade, ele conhece os problemas e as limitações das instituições que pretendem regular o Direito Internacional.

A respeito da Corte Internacional de Haia, por exemplo, ele propõe algumas mudanças que considera urgentes, tais como diminuir a extensão de sua competência, definir o caráter obrigatório de sua jurisdição, reconhecer indivíduos e ONGs como sujeitos de Direito Internacional e introduzir a responsabilidade pessoal dos governantes no que diz respeito a crimes de Direito Internacional. Tudo isso implica a instituição verdadeira de um Código Penal internacional ${ }^{37}$.

Ferrajoli vai ainda mais longe e afirma ser a Soberania uma categoria antijurídica, vez que ela "[...] é a ausência de limites e de regras, ou seja, é o contrário daquilo em que o direito consiste" 38 .

33 FERRAJOLI, Luigi. A soberania no mundo moderno. p. 43.

34 FERRAJOLI, Luigi. A soberania no mundo moderno. p. 29.

35 FERRAJOLI, Luigi. A soberania no mundo moderno. p. 34.

36 FERRAJOLI, Luigi. A soberania no mundo moderno. p. 39.

37 FERRAJOLI, Luigi. A soberania no mundo moderno. p. 54-55.

38 FERRAJOLI, Luigi. A soberania no mundo moderno. p. 44. 
Abem daverdade, apósa RevoluçãoFrancesa (1789), a Soberaniainternae Soberania externa constroem duas histórias paralelas e opostas: "[...] a de uma progressiva limitação interna da Soberania, no plano do direito estatal, e a de uma progressiva absolutização externa da Soberania, no plano do Direito Internacional"39.

Contudo, é patente a deficiência dos meios de coerção do Direito Internacional, pois não invalida as normas internas nem lhes torna menos vinculantes. Seus comandos, a despeito da atividade estatal, continuam sendo comandos jurídicos obrigatórios para os Estados signatários, mas sem força de coação. Nas palavras de Luigi Ferrajoli:

Precisamos recuperar aquela dimensão normativa e axiológica da ciência jurídica internacional, que já foi a de Vitória e de Kant. Num duplo sentido: reabilitando sua função planejadora e, ao mesmo tempo, "levando a sério" o direito, ou seja, reconhecendo que o direito é como o fazem os homens - e, portanto, todos nós, a começar por nós juristas, que não em pequena parte arcamos com sua responsabilidade - e, simultaneamente que o direito é um sistema normativo, de modo que as disposições e os comportamentos efetivos dos Estados em contraste com tal sistema não representam "desmentidos" de suas normas, como muitas vezes lamentam os juristas e os cientistas políticos realistas, mas sim "violações", cuja legitimidade todos temos o dever de denunciar ${ }^{40}$.

Vê-se então que, para Ferrajoli, a Soberania externa vem tomando força com o Estado Constitucional moderno tolhendo seus próprios poderes na sua esfera interna de atuação, ao mesmo tempo que esse mesmo Estado reafirma, de maneira cada vez mais contundente, a sua Soberania perante os demais, sem, contudo, criar mecanismos de Direito Internacional eficazes para fazer valer tais poderes.

\section{CONTRIBUIÇÕES DE BOBBIO E FERRAJOLI À SOBERANIA DE KELSEN}

Kelsen busca principalmente relacionar a Soberania com o aspecto da justificação. Por isso, admite a primazia do Direito Internacional, de modo que a Soberania só pode ser entendida relativamente, isto é, como um ordenamento que só reconhece como superior o internacional, nenhum outro.

39 FERRAJOLI, Luigi. A soberania no mundo moderno. p. 27.

40 FERRAJOLI, Luigi. A soberania no mundo moderno. p. 59-60. 
Nesse sentido, Kelsen transmite que a Soberania não é exercida por um indivíduo ou por um grupo deles, mas, sim, é componente indissociável do poder do Estado, é a manifestação da validade e da eficácia do ordenamento jurídico, que é o que determina o modo de exercer o poder e os seus limites. E esse ordenamento só poderia ser limitado pelo Direito Internacional.

Já Bobbio relaciona a Soberania com o aspecto democrático visando à racionalização e ao disciplinamento jurídico das novas formas de Poder, ou seja, as novas autoridades que estão surgindo.

A tessitura social apresenta uma pluralidade de grupos em competição para condicionar o poder político. Essa pluralidade já impede a existência de uma única autoridade. Isso porque o processo de decisão política é o resultado de uma longa e vasta série de mediações, sem um soberano verdadeiro.

O sociólogo francês Edgar Morin ${ }^{41}$ reforça que "Todos estos riesgos plantean un problema de las instituciones de lo que denominamos 'nuestras democracias desarrolladas'. La des centralización, que ha reforzado el nivel local, sin duda ha debilitado a los poderes centrales".

Como se não bastasse, Bobbio prediz uma crise da Soberania estatal considerando as mudanças do cenário internacional, que chama de "nova Soberania", eis que a colaboração internacional cada vez mais veemente desgasta os poderes tradicionais dos Estados ditos soberanos.

Nesse sentido, Morin ${ }^{42}$ corrobora:

No son sólo las soberanías absolutas de los Estados nación las que impiden la formación de una sociedad-mundo. También es el movimiento tecnoeconómico de la globalización el que, al crear su infraestructura, provoca las resistencias étnicas, nacionales, culturales y religiosas que se oponen a la homogenización mundializadora.

Por sua vez, Ferrajoli faz uma abordagem mais histórica da questão da Soberania. Demonstra que, após 1945 e com o estabelecimento da ONU e a Declaração Universal dos Direitos do Homem, a Soberania deixa de ser uma 41 MORIN, Edgar. La via para el futuro de a humanidad. Madrid: Paidos, 2011. p. 187. 42 MORIN, Edgar. La via para el futuro de a humanidad. p. 21. 
liberdade absoluta e se subordina juridicamente ao imperativo da paz e à tutela dos direitos humanos. É quando ocorre para Ferrajoli a crise da Soberania.

Isso porque a Carta da ONU é um verdadeiro contrato social internacional que estabelece vínculos entre os Estados e uma ordem verdadeiramente universalista, a exemplo do que Kelsen também já defendia.

Novamente Morin ${ }^{43}$ ilustra:

La unificación tecnoeconómica del globo está en crisis. Existe uma coincidencia entre la proliferación de Estados soberanos, el aumento de su interdependencia y su rigidez etnorreligiosa. Esta coincidência no es fortuita. Se explica por: a) las resistencias nacionales, étnicas y culturales a la occidentalización; b) el esmoronamiento generalizado de la esperanza puesta en e! progreso. El progreso, gran mito providencial de Occidente, invadió todo el planeta durante la segunda mitad del siglo XX.

O que passa a existir é uma limitação interna da Soberania no plano do direito estatal e uma progressiva absolutização da Soberania no plano do direito externo (internacional), porém sem mecanismos de coerção, já que as normas internas não são invalidadas pelo Direito Internacional, mas são sobrepujadas pelos Estados signatários.

Exemplo típico e atual é o caso da Hungria. Em 2015, a Hungria foi a principal porta de entrada da Europa para milhares de migrantes do Oriente Médio e da África. O governo húngaro, sob a chefia de Viktor Orbán, ergueu uma cerca na fronteira com a Croácia e com a Sérvia para barrar os estrangeiros. Agora, o bloco europeu discute mudanças nas regras de asilo que iriam exigir que os Estados-membros aceitassem uma cota de refugiados ou pagassem uma multa para realocá-los em outro país. É um exemplo clássico no qual a Soberania da Hungria vem sendo confrontada pela imposição do bloco.

A reflexão de Edgar Morin novamente serve como uma luva. Na visão do sociólogo, "existe una contradicción entre las soberanías nacionales, [...], y la necesidad de unas autoridades supranacionales para tratar los problemas vitales del planeta. Las convulsiones de la crisis de humanidad pueden ser mortales" ${ }^{44}$.

43 MORIN, Edgar. La via para el futuro de a humanidad. p. 22.

44 MORIN, Edgar. La via para el futuro de a humanidad. p. 31. 
O Estado moderno tolhe seus próprios poderes na esfera interna de atuação mediante mecanismos constitucionais e democráticos necessários, mas também afirma a sua Soberania perante os demais Estados, sem, contudo, criar mecanismos de Direito Internacional eficazes para fazer valer tais poderes.

\section{CONSIDERAÇÕES FINAIS}

Em razão dessas considerações, vê-se a importância da Soberania no âmbito interno e externo, instituto em constante transformação e ferramenta de defesa para os Estados no cenário internacional e mesmo como parte da manutenção da democracia intra e interestatal.

Kelsenjá via a Soberania como fruto do ordenamentojurídico. Como manifestação da validade e eficácia da ordem jurídica, que só poderia ser limitada pelo Direito Internacional. Uma matéria a ser regulamentada pelo Direito Internacional tem o efeito de impedir a mesma regulamentação pelo Direito nacional.

Bobbio já aproximava o instituto da Soberania ao de democracia na modernidade como mecanismo de manutenção da independência dos povos. Além de já decantada por ser o resultado de uma longa e vasta série de mediações internas para tomada de decisões políticas, soma-se a flexibilização imposta pela globalização, pois as relações entre os Estados, principalmente de mercado, são cada vez mais internacionalizadas, em escala global.

Ferrajoli, por sua vez, contempla uma limitação interna da Soberania no plano do direito estatal e uma progressiva absolutização da Soberania no plano do direito externo. Tal ideia reforça a de Bobbio, porém complementa que essa absolutização não é seguida de mecanismos de coerção, já que as normas internas não são invalidadas pelo Direito Internacional, nem punem eficazmente o Estado transgressor. Interessante notar que Kelsen entendia que o direito de fazer guerra constitui a coerção de que Ferrajoli sente falta.

Retoma-se oproblema enfrentado, indagando se Bobbioe Ferrajolicontribuíram para os estudos a respeito da Soberania operados por Kelsen dentro da linha do tempo e do contexto histórico próprio. 
Confirma-se a hipótese inicialmente feita de que Bobbio e Ferrajoli fizeram evoluir os estudos de Kelsen acompanhando as mudanças do cenário mundial ao longo do tempo. A Soberania representa o poder popular, um dos elementos do Estado moderno. Inicialmente não podia sofrer intervenção de nenhum outro Estado.

Kelsen já passou a admitir a sua limitação pelo Direito Internacional. Bobbio previa a contradição entre Soberania e democracia e constitucionalismo e tratou do progressivo desfazimento das fronteiras em razão das relações negociais, culturais e jurídicas entre os Estados. Igualmente Ferrajoli diz que já depois da Segunda Grande Guerra, portanto seguidamente à obra de Kelsen, a liberdade absoluta pregada pela Soberania passou a subordinar-se juridicamente ao imperativo da paz e à tutela dos direitos humanos em nível mundial, sem, contudo, criar uma forma de coerção ou coação para tanto.

Essas contribuições apontam para a mundialização de que fala Edgar Morin. Mundialização essa que cria uma infraestrutura de sociedade-mundo que exige uma economia globalizada. É seguida e motivadora de várias crises que se retroalimentam, porém também impõem reformas e fazem nascer uma nova ordem mundial que gera a "nova Soberania", formulada por Bobbio, nessa "era liberal", mencionada por Ferrajoli, capaz de se adaptar à intensa e necessária colaboração internacional para uma mudança rumo ao mundo melhor de solidariedade e fraternidade.

\section{REFERÊNCIAS DAS FONTES CITADAS}

BIOGRAFIAS. Dicionário de Filosofia de Cambridge. Disponível em: < http://educacao.uol. com.br/biografias/francisco-de-vitoria.htm >. Acesso em: 10 ago. 2016.

BOBBIO, Norberto. Liberalismo e democracia. São Paulo: Brasiliense, 2006a.

BOBBIO, Norberto; MATTEUCCI, Nicola; PASQUINO, Gianfranco. Dicionário de política. Tradução de Carmen C. Varriale et al. 13. ed. Brasília: UnB, 2008. Título original: Dizionario di política. 2 v.

CAETANO, Marcello. Manual de Ciência Política e Direito Constitucional. 4 ed. Lisboa: Coimbra Editora, 1963. 
DALLARI, Dalmo de Abreu. Elementos de teoria geral do Estado. Elementos de Teoria geral do Estado. 19. ed. São Paulo: Saraiva, 1995.

DESCARTES, René. Discurso do método. Trad. Maria Ermantina Galvão G. Pereira. São Paulo: Martins Fontes, 1999.

FERRAJOLI, Luigi. A Soberania no mundo moderno. Tradução de Carlo Coccioli e Márcio Lauria Filho. São Paulo: Martins Fontes, 2002. Título original: La sovranità nel mondo moderno.

KELSEN, Hans. Teoria geral do direito e do estado. 2. ed. (1 ${ }^{\text {a }}$ reimpressão), trad. Luís Carlos Borges, São Paulo: Martins Fontes, 1995.

KELSEN, Hans. Teoria pura do direito. Trad. João Baptista Machado, 6. ed., São Paulo: Martins Fontes, 1998.

MORIN, Edgar. La via para el futuro de a humanidad. Madrid: Paidos, 2011. Título original: La Voie.

PASOLD, Cesar Luiz. Metodologia da pesquisa jurídica: Teoria e Prática. 13. ed. rev. atual. e ampl. Florianópolis: Conceito Editorial, 2015.

SASSEN, Saskia. Bordering Capabilities versus Borders: Implications for National Borders. 30 Michigan Journal of International Law (2008-2009). p. 567-597. 